\title{
El Ilustre y Real Colegio de Abogados de México, ¿una corporación política?*
}

\author{
Maria del Refugio González
}

II-UNAM

INTRODUCCIÓN ${ }^{1}$

$\mathbf{P}$ or real cédula de 21 de junio de 1760 se aprobaron los Estatutos que habrían de regir la vida corporativa del Ilustre y Real Colegio de

* Trabajo presentado en el seminario "Gobierno y política en las ciudades mexicanas, 1808-1917", México, Instituto de Investigaciones Dr. José María Luis Mora, 18-19 de septiembre de 1991

1 Parte del material utilizado procede de "Los abogados y el Colegio de Abogados en la transición al México independiente", VIII Reunión de Historiadores Mexicanos y Norteamericanos, San Diego, California, 18-20 de octubre de 1990. Esos materiales tienen aquí otra lectura; aquí se revisó la redacción y, aunque se recogen algunas partes del trabajo anterior, se introducen también nuevos materiales.
Abogados de México. El rey erigió en colegio

la clase de los profesores de la abogacía, con el loable piadoso fin de unirse y estrecharse honrosamente, y de socorrer las necesidades de los mismos abogados en los casos de urgencia, y sus familias, de viudas y huérfanos por la infelicidad y miseria a que suelen quedar reducidos. $^{2}$

Esto daba a la corporación un carácter eminentemente mutualista. Sin embargo, además de las funciones que por estatuto tenía, el colegio fue adquiriendo un poder político que se

\footnotetext{
${ }^{2}$ Estatutos, 1808.
} 
derivaba, en alguna medida, aunque no exclusivamente, del saber jurídico de sus miembros. ¿Cuál fue el alcance de sus funciones y cuál el peso de la corporación en el seno de la sociedad novohispana? ¿Cuál era la importancia del cuerpo de abogados? ¿Qué papel jugaban sus miembros? Éstas y muchas otras cuestiones pueden plantearse. No tenemos para todas todavía respuesta y no es en este ensayo que se resolverán, ya que su objetivo es más modesto. Se busca solamente hacer una clescripción de la participación del colegio y de sus miembros en los años previos a la independencia, especialmente los que se corresponden con los intentos autonomistas de los criollos novohispanos. En ellos se puede ver el carácter político de la corporación. Previamente se hace una serie de consideraciones sobre los abogados dentro de la sociedad, sobre los colegios de abogados y sobre la manera en que se fundó y desarrolló el de México.

\section{LOS ABOGADOS Y LOS COLEGIOS DE ABOGADOS}

Desde muy antiguo los conocedores del derecho ocuparon diversos cargos tanto en la administración pública como en la de justicia. En el imperio romano los sujetos que tenían este conocimiento desempeñaron oficios muy variados: jurisconsultos; burócratas; asesores; escritores de derecho; consultores; académicos; oradores forenses; abogados y escribanos. ${ }^{3}$ En la alta Edad Media no hubo un lugar específico para el conocedor del dere-

\footnotetext{
${ }^{3}$ Schulz, History, 1967.
}

cho ya que las instituciones de las que habían dependido desaparecieron de la escena pública. A partir del siglo XII, en las universidades europeas, comenzaron a formarse profesionales de la ciencia juridica, que encontraron acomodo en las diversas cortes, ${ }^{4}$ y que proporcionaron a los reyes las bases doctrinarias para el fortalecimiento de su poder frente a los estamentos tradicionales.

El reconocimiento del lugar privilegiado que ocupaban en la sociedad les permitió generar una conciencia estamental que los llevó a buscar el medio para proteger sus intereses. Hacia el siglo XIV estos sujetos comenzaron a agruparse en cofradías de letrados y el primer Colegio, ya no co. fradía, que se fundó en España, parece que fue el de Barcelona, en $1330 . .^{5} \mathrm{La}$ incorporación al Colegio se volvió re. quisito indispensable para acceder al ejercicio de la profesión; así pues,' a más del carácter mutualista, la corporación comenzó a tener el poder político derivado del control del ejercicio profesional. ${ }^{6}$ La enseñanza especializada y la colegiación obligatoria permitían la conservación de sus privilegios. ${ }^{7}$

\section{Los abogados y el colegio en Nueva España}

La implantación de instituciones castellanas en tierras americanas hizo ne76.

Maravall, "Formación", 1953, pp. 65-67 y

5 Bermúdez Aznar, Contribución, 1969, pp. 16-17.

6 Ibid., p. 20.

${ }^{7}$ Ibid., p. 72 
cesaria la presencia de sujetos formados en el conocimiento del derecho para desempeñar los oficios que se creaban en las diversas instancias de la administración pública. Para responder a esta demanda fue preciso reproducir, de este lado del Atlántico, las instituciones que en la península habían servido para la formación del conocedor del derecho. De esta manera, la formación empírica de las primeras décadas posteriores a la conquista fue sustituida por la enseñanza sistemática y escolarizada a partir de la fundación de la Real Universidad de México en 1551. No todos los que ahí se formaban eran abogados propiamente dichos $^{8}$ ya que para ser mere. cedor de este nombre debía probarse el conocimiento de las leyes del reino ante las audiencias de la localidad. ${ }^{9}$

Por más de doscientos años, los abogados novohispanos no tuvieron una corporación que los agrupara de manera orgánica. En 1759 solicitaron la erección de lo que sería un Colegio de Abogados bajo las reglas y constituciones del de Madrid. Con este fin, se elaboró un proyecto de estatutos que fue aprobado por el rey el 21 de junio de 1760 . Como se dijo, el objetivo del Colegio era la protección de viudas y huérfanos y de los abogados viejos o pobres. ${ }^{10}$ Sin embargo, por la colegiación obligatoria, el cuerpo ad-

${ }^{8}$ Gonźllez, Ensenanza, 1987, pp. 25-31.

9 Desde 1505, en las Leyes de Toro se esta. bleció este requisito de acceder a los diversos oficios del Consejo, las audiencias y cancillerías o cualquier otro tribunal, ley 2 de Toro, en ley 4, tit. 1, libro II, Nueva Recopilación de Castilla y ley 5 , tít. II, libro III, Novisima Recopilacion.

to véase Estatutos, 1830 , p. 3, cédula real, s.p.

El ILUSTRE y REAL COLEGIO DE ABOGADOS quirió una gran importancia, aunque, como se verá, en Nueva España no todos los abogados se hallaban matriculados en él. En 1794, el rey concedió la fundación del brazo docente, de cuño ilustrado, del Colegio de Abogados: la Academia de Jurisprudencia Teórico Práctica, la cual recibió sus constituciones en 1811.11

La erección de ambas instituciones muestra la presencia en Nueva España de un grupo urbano, asentado sobre todo en la capital del virreinato, que llegó a tener una influencia importante en diversos sectores de la burocracia civil y de la eclesiástica aunque tuviera también intereses propios, corporativos.

En relación con la pirámicle social del virreinato, este grupo se constituyó con sujetos de diversos orígenes. A su formación contribuyeron el creciente aumento de los litigios y la constante ampliación tanto del gobierno temporal como del espiritual, compuestos, en buena medida, por sujetos que debían su prestigio y su lugar en la sociedad a sus conocimientos y no a su nacimiento; estos sujetos eran los conocedores del derecho.

\section{La posición social y los privilegios de los abogados novobispanos}

E1 conocedor del derecho tuvo un alto rango social en Nueva España, en cuyo territorio podía desempeñar los más variados cargos. ${ }^{12}$ Para 1788 en

11 González, "Academia", 1982, p. 305 y "Práctica", 1984, pp. 281-308.

12 Por su sola formación jurídica no podían ser alcaldes mayores, corregidores o subdelega- 


\section{SECUENCIG}

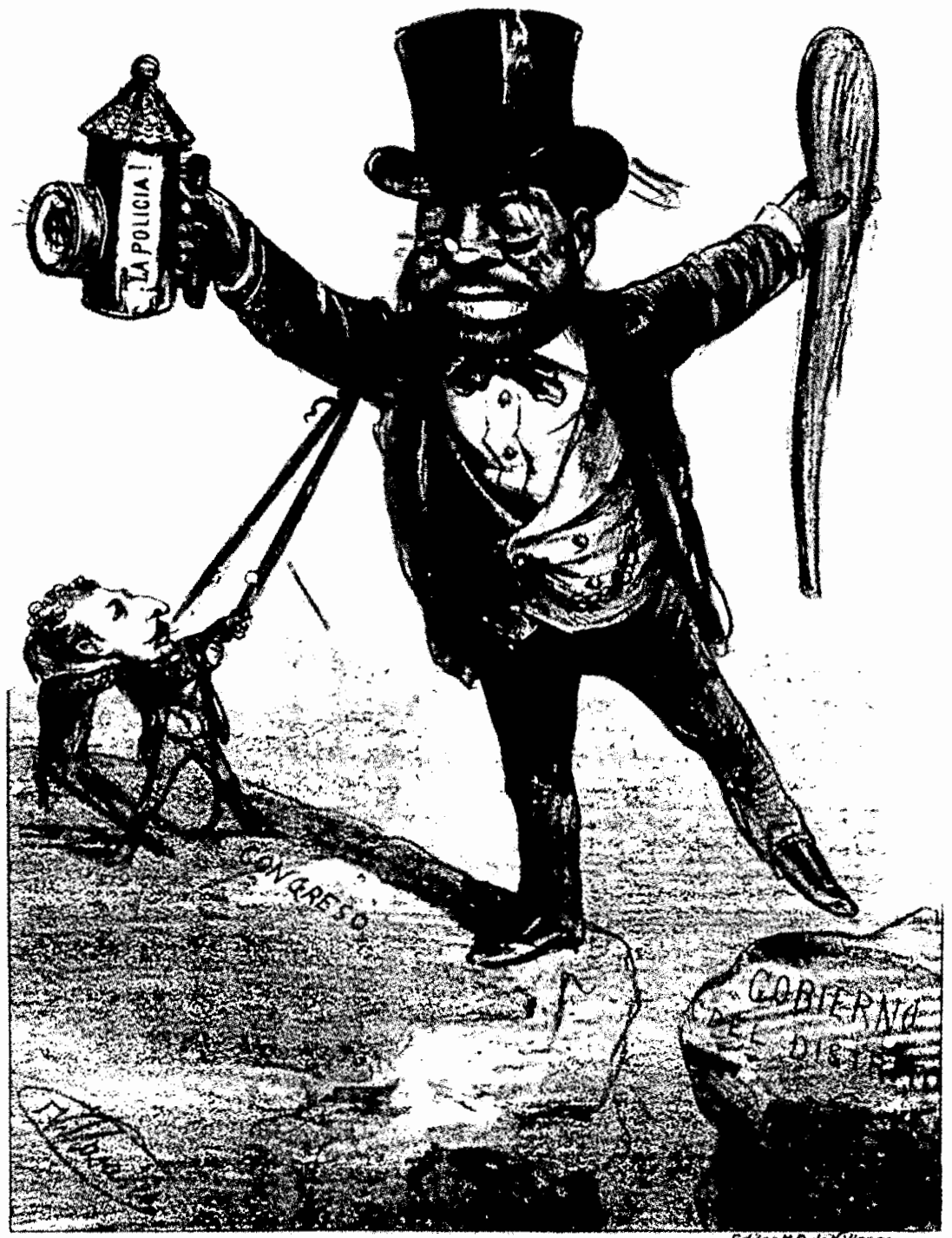

He aquiun Coloso próxımo á perder el equilibrio. 
la capital del virreinato había 225 conocedores del derecho matriculados en el colegio; entre ellos se hallaban curas, relatores, canónigos, catedráti$\cos$, asesores de las diversas rentas reales, conciliarios, prebendados, escribanos, abogados de presos y de indios, presbíteros, agentes fiscales y un amplio número de abogados, propiamente dichos. ${ }^{13}$

La composición social novohispana era diferente a la española; en el virreinato los abogados formaban parte de la cúspide de la pirámide social tanto por su formación jurídica como porque no eran miembros de los grupos conquistados.

El paso por la universidad ${ }^{14}$ y la academia les proporcionaba los conocimientos jurídicos y los vínculos y amistades que harían posible su tránsito hacia posiciones de $\operatorname{poder}^{15}$ que en la

estos oficios fueran designados catedráticos de jurisprudencia; Archivo General de la Nación (AGN), Escribanos, vol. 22, exp. 10. véase infra nota 14.

13 "Lista de los abogados del Ilustre Colegio de $A$ bogados que actualmente residen en esta corte, con expresión de su antigüedad en examen, como lo denotan los números del margen, y empleos que obtienen en el Colegio. Sirve para el presente ańo de 1788", Biblioteca Nacional de México. Pocos años antes, en 1782, en la península había más de diez mil abogados, Pérez de Villamil, Disertacion, s.a. (pero de 1782 O 1783), citado por Mariluz Urquijo, "Teatro", s.a.

14 Entre 1751 y 1808 , en los tribunales se inciementó el número de sujetos que procedían de la cáredra; Burkholder y Chandler, Impotencia, 1984, pp. 172-173.

15 la carrera judicial, por ejemplo, dependía en buena medida de las relaciones personales del sujeto, éstas más que el talento o la brillantez eran el factor que determinaba la fortuna de una persona en la burocracia letrada, ibid., pp. 1516 y 107. península hubiera sido dificil alcanzar con la sola formación en derecho, a más de que los graduados de la primera, desde 1563 , eran considerados caballeros. ${ }^{16}$

A lo largo de todo el periodo colonial, la clase jurista ocupó un lugar destacado en la sociedad, pero tal parece que la constitución del Colegio de Abogados se dio en el momento en que esta clase consolidaba su posición. Por lo menos es lo que se desprende de la legislación dictacla en el último tercio del siglo XVIII. En 1772, la corporación solicitó y consiguió que sus miembros civiles, oidores, relatores, fiscales, etc. ${ }^{17}$ usaran clistintivos "de bolillos" para diferenciarse de los otros sectores de la sociedad. El mismo privilegio les fue concedido en 1799 a los miembros eclesiásticos, entre los cuales había obispos, dignidades, individuos de los coros, provisores, curas beneméritos "y generalmente los sujetos de más viso del venerable clero indiano". ${ }^{18}$ Descle 1775 se había ordenado que los abogados gozaran de las libertades personales y exenciones de los gravámenes de que disfrutaba la clase noble; asimismo estaban libres de cargas concejiles, sin derecho alguno a pretender que se les eligiera para los oficios de justicia por el estado noble; se dispuso también que los graduados en las universidades mayores gozarían de los privilegios concedidos por la Recopilación de Castilla, esto es, el de no pechar: ${ }^{19}$

16 Plaza y Jaén, Crónica, 1931, vol. 1, p. 64.

17 AGN, Escribanos, vol. 22, exp. 5, ff. 51-64.

${ }_{18}$ AGN, Escribanos, vol. 23, exp. 5, ff. 68-82.

19 Véase, "Auto del Consejo de Castilla de 28 de enero de $1775^{\circ}$, en nota 2 a la ley $\mathrm{x}$, título vi, libro I de la Recopilactón de Castilla. 
La conciencia de sus privilegios los llevaba a defenderlos. En 1799, el Colegio de Abogados protestó porque algunos de sus miembros habían sufrido ciertos "desaires". En el escrito correspondiente se afirmaba que los abogados componían "la milicia togada que goza de las mismas excepciones que la armada", y que entre los nobles e hidalgos y los letrados las leyes "no ponen más diferencia sino la de que los primeros nacen con el privilegio, y los segundos lo adquieren por sus propias luces".20

En una sociedad con escasos nobles verdaderos y muchos grupos absolutamente marginados del desarrollo social "a la española", parece bastante comprensible que los abogados se sintieran nobles. En Europa su condición no podía ser ni remotamente equiparada a la de la nobleza, pero aquí eran casi nobles, "nobles de letras".

Parece claro que aunque los abogados novohispanos se sintieran "nobles" por sus conocimientos y por estar a cargo de los negocios de los más beneméritos ciudadanos, los del Estado, el trono y los de la Iglesia, ${ }^{21}$ el rey no los consideraba tales, sino a los que lo eran realmente ${ }^{22}$ al margen de sus estudios de derecho y su influencia en la sociedad. Entre la "nobleza" de los abogados y la de los nobles, la dife70 .

${ }^{20} \mathrm{AGN}$, Escribanos, vol. 23, expediente 5, f.

21 Ibid., f. 71.

22 Incluso una real deliberación de $17 \mathrm{de}$ noviembre de 1765 ordenó que "dicho $N$. por razón de su profesión, y de la nobleza personal que por ella adquiere, debe tener su asiento en la clase de regidores nobles y preferir a los modernos [...] sin que sea visto declararle nobleza alguna de sangre", ibid., ff. 72 y $72 v$. rencia no era de grado sino de origen: los primeros no eran nobles sino que tenían privilegios de noble. Por con. servarlos habrían de luchar cuando los acontecimientos pusieron en peligro lo mucho que como cuerpo fueron ganando.

\section{El Colegio de Abogados al final de la época colonial}

Para el análisis del comportamiento político de la corporación conviene saber quiénes eran sus miembros, lo que se puede ver fácilmente en el censo de $1805,{ }^{23}$ elaborado en respuesta a la orden de 1802 que mandaba averiguar el número de abogados asentados en el virreinato. ${ }^{24}$

Este censo enlista a todos los individuos, vinculados o no a la corporación, que ejercían los diversos oficios relacionados con la profesión jurídica y contiene el número más preciso posible de este grupo social poco antes de que se presentaran los hechos que culminaron con la independencia. Por ello puede servir de base para ana. lizar el comportamiento del colegio y de sus miembros en el periodo inmediato anterior a la independencia. Los datos son los siguientes:

23 El censo está en AGN, Escribanos, vol. 22, exp. 10, ff. 254-276, antecedidas de más de doscientas fojas de documentación, que entre otras cosas, muestra que solo en las pocas ciudades importantes del reino de Nueva España, especialmente en México, había un número más o menos amplio de abogados.

24 La real onden se inscribe dentro de la política de finales del siglo xvin que buscaba reducir su número, véase, Arenal Fenochio, "Abogados", 1980, pp. 544-549. 
En la corte se hallaban: 123 individuos matriculados y 37 no matriculados que ejercían la profesión, y 71 individuos matriculados que no la ejercían por encontrarse desempeñando un cargo de relator, agente fiscal, asesor, etc. en los varios tribunales, o por desempeñar otros oficios que los inhabilitaban para el ejercicio de la abogacía. Fuera de la corte se hallaban: 14 individuos matriculados (tres en Puebla, dos en Oaxaca, dos en Guanajuato, y Atlixco, Tacuba, Querétaro, San Miguel el Grande, Maravatio, Xalapa y Toluca con uno cada una); 73 individuos que ejercían la profesión sin estar matriculados (16 en Puebla, nueve en Valladolid, ocho en Oaxaca, siete en Guanajuato, cinco en Querétaro, cinco en San Luis Potosí, cuatro en Pátzcuaro, tres en Toluca, dos en Veracruz, lo mismo que en Córdoba, Mérida y San Juan de los Llanos, y uno en Zamora, lo mismo que en Tlalpujahua, Lerma, Xalapa, Tenango del Valle e Ixmiquilpan); 35 individuos matriculados pero que no ejercían su profesión por ser curas, clérigos ordenados in sacris, o porque tenían comodidades y no necesitaban ejercerla (seis en Puebla, tres en Cuautituán, dos en Valladolid, uno en cada localidad: Veracruz, Orizaba, Perote, Durango, Oaxaca, Zacatecas, San Luis Potosí, Sierra de Pinos, Otumba, Sayula, Atitalaquia, Celaya, Tecicapan, Tulancingo, Malacatepec, Tacubaya y Coyoacán); 33 individuos que no se hallaban en la corte ni matriculados, ni ejerciendo la profesión, algunos de ellos por las mismas causas que los anteriores (seis en Puebla, cuatro en Querétaro, mismos en
Valladolid, Guanajuato y Oaxaca, dos en Cuautitlán y uno en cada localidad: Veracruz, Cuernavaca, CoatepecChalco, Orizaba, Córdoba, San Luis Potosí, Real de Santa Anna y León).

Sólo unos cuantos de estos abogados tenían comodidades suficientes para vivir sin necesidad de ejercer la profesión. El total era de 386 y los abogados pudientes se localizaban entre los miembros de tres de los subconjuntos enlistados en el censo, al lado de clérigos y curas; dentro de este grupo -que es minoritario- se encontraban los abogados que no requerían del ingreso derivado del ejercicio profesional. Este dato permite ubicar a los abogados en la misma categoría que sus colegas europeos, que ocupaban un lugar privilegiado en la sociedad, pero debían trabajar para vivir.

Antes de pasar a analizar el desempeño político de la corporación, conviene señalar que el Colegio de Abogados era, a los 35 años de su fundación, un cuerpo consciente de su estatus privilegiado y dispuesto a defenderlo y conservarlo, ya que como bien señala Tocqueville:

Los hombres que han hecho un estudio especial de las leyes, han aprendido en estos trabajos hábitos de orden, cierto gusto de las formas y una especie de amor instintivo hacia el encadenamiento regular de las ideas, que los hace naturalmente opuestos al espiritu revolucionario y a las pasiones irrenexivas de la democracia. ${ }^{25}$

25 Tocqueville, Democracia, 1987. 
EL DESEMPEÑO POLÍTICO

DE LA CORPORACIÓN

La experiencia jurídica romana enriquecida con la reflexión filosóficojurídica de los canonistas conformó un gran conjunto de conceptos, normas y doctrina de una riqueza tal que permitió que, desde el mundo del derecho, frente a circunstancias dadas, los conocedores de estas materias hayan podido aprovecharse de ese rico bagaje para defender sus ideas y posiciones políticas. El conocimiento jurídico aprendido en los largos años de formación podía ser, si se tenía algún fin específico y se elegían a los autores adecuados, utilizado para sustentar una tesis o su contraria. De ahí que no deba extrañarnos que en el proceso que condujo a la independencia, los abogados hayan podido encontrar una fundamentación jurídica para las más diversas posiciones, ${ }^{26}$ tanto las que se ubicaron en los extremos políticos como las que se mantuvieron dentro de los límites de la legalidad imperante.

En el periodo que va de 1808 a 1815 es posible localizar colegiales dentro de todas las tendencias políticas en que se comprometieron los habitantes de Nueva España a partir de la abdicación de Fernando VII. Hay, pues, abogados del colegio entre los Guadalupes; ${ }^{27}$ hay abogados del cole-

26 Guedea, "Busca", 1990.

27 "Nómina de algunas personas pertenecientes a la asociación de los Guadalupes o a ella adictas", en De la Torre Villar, "Guadalupes", 1966, pp. Lxxvi y Lxuı. En las listas de letrados vinculados o adictos a la asociación están Carlos María de Bustamante, Wenceslao Sánchez gio entre los propuestos por Morelos para integrar el Congreso de Chilpancingo y los órganos de gobierno que de él emanaron; ${ }^{28}$ los hay entre quie. nes fueron suspendidos de sus em. pleos por haber sido electos a componer la Junta Suprema Nacional del Reino; ${ }^{29}$ los hay entre los diputados a las Cortes españolas en $1810 ;^{30}$ los hay entre los que suscribieron el Decreto Constitucional para la libertad de la América Mexicana de 22 de octubre de $1814 ; 31$ y los hay, por último leales a la causa del rey. ${ }^{32}$

El despliegue de sus miembros hacia las diversas opciones del universo político no implicó al cuerpo, el cual, lo mismo que varios de sus miembros más conspicuos, no fue demasiado le. jos en sus planteamientos políticos. Al contrario, y si bien durante algún tiempo pareció incluso involucrado en

de la Barquera, Juan Guzmán y Raz, Félix Lope de Vergara y Antonio López Matoso, miembros destacados del Colegio de Agobados.

28 Hernández y Dávalos, Historia, 1985, vol. v, pp. 159-160, 296-297. Los mencionados son: Carlos María de Bustamante, José Sorero Castañeda, Mariano Castillejos, Benito Guerra y Francisco de Azcárate, miembros del Colegio según el censo de 1805.

29 De la Torre Villar, "Guadalupes", 1966, pp. 74-75. Del Colegio son: Torres Caฉnño, Flores Alatorre, Gómez Eguiarte, Peimbert, Castillejos y Bustamante.

30 Juan José Güereña, por Durango; José Beye de Cisneros, por México y José Miguel Guridi y Alcocer, por Tlaxcala, véase, Berruczo, Participación, 1986, pp. 55-112.

31 José Sotero Castañeda, diputado por Durango y Carlos María de Bustamante, quien no pudo firmar, véase Hernández y Dávilos, Historia, 1985, t. v, pp. 719-720.

32 Juan Martín de Juanmartiñana quien participó en los interrogatorios para encausar al virrey Iturrigaray, véase, Hernández y Dávalos, Historia, 1985, t. I, pp. 628-629. 
el movimiento autonomista, pronto se replegó hacia la institucionalidad conservadora.

No puede negarse que los individuos del colegio fueron protagonistas en los sucesos que culminaron con la independencia. Este hecho también tiene su razón de ser. Siguiendo a Alexis de Tocqueville, puede decirse que en diversos procesos y movimientos sociales, los letrados condujeron la acción espontánea de los que no lo eran; en estos movimientos siempre hubo nobles y conocedores del derecho "en las primeras filas de todos los partidos". A decir de este autor, casi toclos los movimientos democráticos del mundo, de aquella época, fueron dirigidos por nobles, ${ }^{33} \mathrm{y}$ aunque los abogados no eran nobles propiamente dichos, sí formaban parte -como se señaló- de la nobleza de le. tras que se hallaba en la cúspide de la pirámide social del virreinato. Un buen número de los casi 500 abogados de Nueva España ocupaban puestos importantes en la burocracia civil y la eclesiástica y formaban parte del reducido sector de la población que había conseguido una amplia movilidad social con el producto de su trabajo. Resulta claro que, frente a la posibilidad de perder posiciones y privilegios, optaran -por lo menos el cuerpo en su conjunto- por buscar la conservación de lo que tenían.

\section{Los años del empeño autonomista}

En esos años la situación del colegio parece estable y claramente con-

33 Tocqueville, Democracia, 1987 , vol. 1, pp. 628 y 629.

EL ILUSTRE Y REAL COLEGIO DE ABOGADOS solidada. Al frente de la corporación estuvo entre 1806 y 1811 don Antonio Torres Torija; quien era bien visto por sujetos francamente conservadores como Agustín Pomposo Fernández y Sansalvador y Basilio José Arrillaga, y otros que fueron insurgentes o proinsurgentes como Torres Cataño, Benito José Guerra, Primo Verdad, Flores Alatorre, Bustamante, Juan Nazario Peimbert, Julián de Castillejos, López Matoso, Azcárate y Félix Lope de Vergara, e incluso Beye de Cisneros; ${ }^{34}$ antes de que las circunstancias los obligaran a tomar posiciones radicales, estos sujetos eran colegas y quizá incluso a migos en el seno de la corporación.

Muchos eran los méritos que se le atribuían a Torres Torija; por ello, el colegio pedía una y otra vez su reelección. De entre ellos podemos extraer la información sobre el papel que jugaba el colegio hacia el final de la primera década del siglo XIX. A juicio de los colegiales, por haber levantado al colegio la permanencia de Torres Torija al frente del mismo le daría el "mayor lustre y esplendor", además de que había conseguido "establecer perpetuamente la más estrecha y apreciable armonía entre la nobilísima ciudad y el mismo Colegio" y logrado que el superior gobierno la honrara y distinguiera pasándole "de propio modo que a los tribunales, direcciones y ministros, las reales cédulas y órdenes que contienen decisiones generales desde cl año de $\mathbf{1 7 2 5}$ hasta el día" y que el virrey distinguiera al rector "comisionándole para el desempeño de negocios arduos y delicados". 35

34 AGN, Escribanos, vol. 23, expediente 9, ff. 99-113.

35 Ibid., ff. 114-116v. 
Asimismo se le reconocían: la mejora de las finanzas del colegio; sus esfuerzos por avenir a los tribunales y a los abogados en casos de demandas contra éstos; su empeño por conservar el esplendor de la corporación logrando la incorporación o matriculación en ella de los señores ministros de la Audiencia, la Real Sala del Crimen y de otras personas de conocido prestigio $y$ haber dado debido cumplimiento a la disposición del establecimiento de la Real Academia de Jurisprudencia "que tanto honor $y$ utilidad va a traer a la nación". ${ }^{36}$

$A$ la luz de lo que dice este escrito, poco antes de que en Madrid abdicara Carlos IV en favor de Fernando VII, la mayor parte de la burocracia civil superior y municipal estaba en el Colegio de $A$ bogados o en muy buenos términos con él, incluido el virrey Iturrigaray. Ia corporación, por otra parte, jugaba un papel político importante en los planes autonomistas de la época. El curso de los acontecimientos frustró estos planes, cuyo alcance no nos es cabalmente conocido.

En julio de 1808 el Ayuntamiento de México, frente a los graves sucesos de la metrópoli, elaboró la famosa representación en que se sostenía que, en ausencia del rey, la soberanía residía "en todo el reino, y las clases que lo forman, y con más particularidad en los tribunales superiores que lo gobiernan". ${ }^{37}$ Dos miembros del Colegio de Abogados, Primo de Verdad y Azcárate, impulsaron la propuesta, la cual de alguna manera sirvió de base para que en las reacciones siguientes

$36 \mathrm{lbid}$, ff. 118 y $118 \mathrm{v}$.

37 El texto del Acta, en Tena Ramírez, Leyes, 1976, pp. 4-20. se radicalizara o se matizara esta posición. Poco después, en la junta de 9 de agosto, presidida por el virrey, con la presencia de todos los funcionarios del reino, se proclamó rey de España y de las Indias a Fernando VII y se juró lealtad a la Casa de Borbón, al tiempo que se desconocían a las autoridades impuestas por los franceses. Se convino en que el virrey era el legal y verdadero lugarteniente del rey, y el encargado de la conservación y defensa del reino y que la Audiencia, los demás tribunales y autoridades se mantenían en sus facultades. Entre las firmas está la del licenciado Antonio Torres Torija como representante del Colegio de Abogados, ${ }^{38}$ con lo que el cuerpo quedó en una posición menos radical que la sostenida por Azcárate y Verdad.

La acción del rector tiene un significado especial porque el cuerpo apare. cería como presuntamente vinculado a la postura de fray Melchor de Talamantes, sospechoso de infidelidad al rey y de adhesión a las doctrinas de la independencia. En los escritos que le fueron confiscados hay por lo menos dos referencias al Colegio de Abogados que hacen pensar en un nexo estrecho entre el fraile mercedario y algunos de los miembros del cuerpo. Talamantes declaró que en la disputa entre la Real Audiencia y la nobilísima ciudad respecto de la convocatoria a las ciudades, villas y lugares para la celebración del Congreso, viendo que la situación era muy delicada y

${ }^{38}$ Hernández y Dávalos, Historia, 1985, vol. I, p. 513. 
que el gobierno podía comprometerse en cualquiera de los dos partidos que tomase, creyó que era un medio prudente $y$ adaptable a las circunstancias, tomar el dictamen del Colegio de Abogados. 39

Pero no paró ahí la cosa.

Al escrito del 2 de septiembre del virrey Iturrigaray para consultar al Real Acuerdo sobre la conveniencia de que en las circunstancias que se vivian hubiera en la capital quienes legítimamente representaran a todos los pueblos, los fiscales Borbón, Sagarzurieta y Robledo contestaron airados que, si no se engañaban, lo que quería el virrey era "convocar a un Congreso o juntas de las ciudades y villas del distrito de este virreinato". ${ }^{40}$ Los fiscales y el Real Acuerdo señalaron al virrey que dicha convocatoria estaba reservacla a la soberanía y no podía hacerse sin el mandato del soberano; añadieron que el papel que en España jugaban las Cortes era jugado en América por los oidores de la Audiencia. ${ }^{41}$

Sin el apoyo de otros testimonios es difícil precisar hasta qué punto estaban involucrados los colegiales en este proyecto. Pero cualquiera que haya sido el alcance del sueño autonomista cabe decir que poco más duró ya que la noche del 15 al 16 de noviembre fue arrestado el virrey Iturrigaray, cabeza

39 García, Documentos, 1910 , vol. vi, p. 72.

to Hernández y Dávalos, Historia, 1985 , tomo I, pp. 530-531.

41 Causa instruida a fray Melchor de Talamantes, en García, Documentos, 1910, vol. vi, pp. 482 y 483 . El proyecto completo de las funciones del Congreso Nacional Americano del fraile mercedario, en Hernández y Dávalos, Historia, 1985, vol. I, p. 494.

EL ILUSTRE Y REAL COLEGIO DE ABOGADOS más o menos visible o instrumento del proyecto autonomista.

Ya bajo el mando político y militar del virrey Garibay se hizo una relación de los pasajes más notables ocurridos en las juntas convocadas por su antecesor los días 9 al 31 de agosto y 1 y 9 de septiembre de 1808 . En ella se da cuenta de lo que se dijo en aquellas reuniones destacando el desacuerdo de los presentes con la tesis autonomista de Primo Verdad, la cual habia sido calificada de "sediciosa y subversiva" $y$ "proscrita y anatematizada" por algunos de los miembros del alto clero. La relación es de 16 de octubre de $\mathbf{1 8 0 8}$ y fue suscrita por todas las autoridades civiles del virreinato y los representantes de los cuerpos mineros, comerciales y abogados. ${ }^{42}$ La firma de Torres Torija en su carácter de rector del Colegio de Abogados dejó nuevamente a salvo de sospechas de infidencia a la corporación aunque, por otro lado, sus miembros seguían siendo objeto de imputaciones.

En la averiguación que realizó la Audiencia a finales de octubre sobre la conducta de Iturrigaray, de entre los interrogados tanto Carlos Camargo, del Colegio Mayor de Todos Santos, ${ }^{43}$ como Juan Martín de Juanmartiñana, del propio Colegio de Abogados, ${ }^{44} \mathrm{di}$ jeron que alrededor del 11 de septiembre había corrido la especie de que los oidores Ciriaco González Carbajal, Guillermo Aguirre, Miguel Bataller y Ambrosio Sagarzurieta iban a ser separados en sus empleos por el virrey,

\footnotetext{
42 Ibid., vol. I, pp. 617 y ss.

43 Ibtd., vol. I, pp. 636-637.

41 Ibtd., vol. I, pp. 628-629.
} 


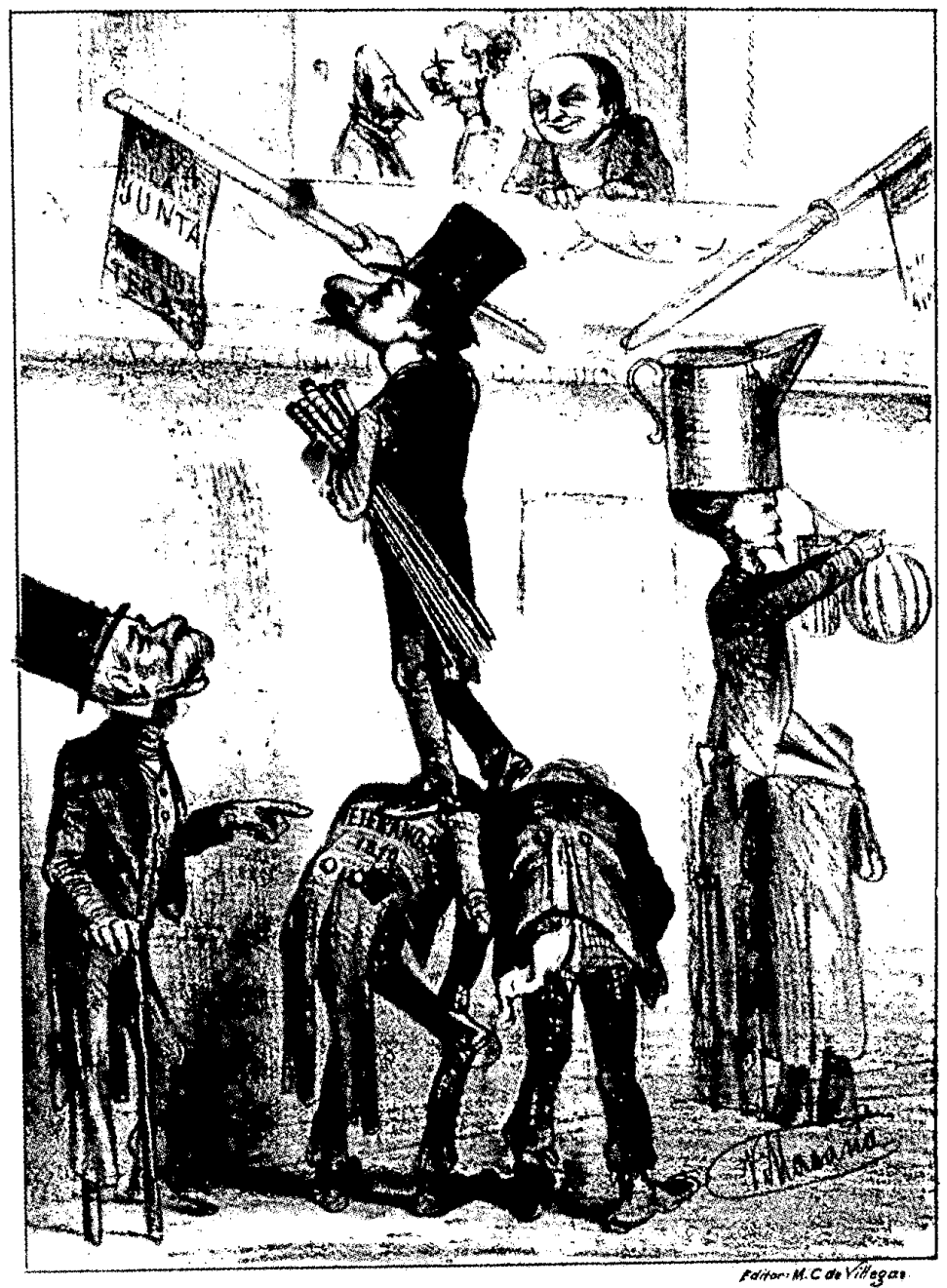

Esa junta patriótica olvida los cimientos parque llegó á cierta altura. 
para poner en su lugar a los licenciados Cristo, Torres Torija, Verdad y Azcárate, miembros conspicuos del Colegio de Abogados.

No para ahí la participación de miembros del colegio en los planes autonomistas o de franca insurrección de aquellos años. En el año 1809 algunos colegiales fueron encausados por haber tratado de independizar a Nueva España, otros más encabezaron conjuras contra el régimen, en el primer supuesto se hallaba Julián de Castillejos y, en el segundo, Francisco de la Concha, cura del Sagrario de Valladolid. Tenemos, pues, que durante los años del empeño autonomista, el cole. gio se mantuvo dentro de la ortodoxia institucional, aunque parece bastante claro que, incluido su rector, el cuerpo parecía simpatizar con la causa, hasta que se inició la insurrección encabe. zada por Hidalgo.

\section{La reacción frente a la insurrección}

Los acontecimientos que se sucedian en España y en Nueva España llevaron al colegio a optar por la institucionalidad; no otra cosa sugieren los testimonios que de esos años han llegado a nosotros. Los que optaron por las posiciones insurgentes fueron abandonando el colegio incorporándose a los ejércitos de Hidalgo y de Morelos. Veamos los hechos.

El año de 1810 se inicia en el seno del Colegio de Abogados con la consabida petición para la reelección de Torres Torija, con la firma de tan sólo 21 miembros, entre los que están Peimbert, Primo de Rivera, García y García,
López Matoso, Torres Cataño, Benito José Guerra y otros. El fiscal de la Audiencia, que era todavía Sagarzurieta, no parece haberse hecho eco de la denuncia de Talamantes y muestra su satisfacción por la petición. ${ }^{45}$

Reelecto su rector, el Colegio de Abogados no volvió a manifestarse públicamente hasta el 29 de octubre de 1810. Mientras tanto, en toda América se habían generalizado las declaraciones de independencia y en España se continuó el proceso para la conformación de las Cortes. Las autoridades novohispanas habían juraclo obediencia a la regencia el 7 de mayo del año 10; en el gobierno local se sucedieron la Audiencia gobernadora (mayo-septiembre) y Francisco Xavier Venegas. El proceso para la elección de diputados a Cortes continuó y lo mismo sucedió con las conspiraciones contra el gobierno, la más importante de las cuales estalló el 16 de septiem. bre en el pueblo de Dolores.

La rebelión fue condenada por las cabezas del gobierno temporal, Vene. gas, y del espiritual, Lizana y Beaumont, quienes conminaron a sus seguidores a abandonarla; el incumplimiento sería penado con prisión y excomunión. El Estado y la Iglesia exhortaron a los súbditos de Nueva España para que no se "dejaran seducir de las engañosas apariencias de otra constitución diversa de la en que nos hallamos". ${ }^{46}$

El proceso para elegir diputados a

45 $A G N$, Escribanos, vol. 23, expediente 9, ff. 162-170.

46 González del Campillo, Pastoral, 1810, 
las Cortes de Cádiz siguió su curso y el 1 de octubre del año de 1810 se dieron a conocer los nombres de los 17 diputados que representarian a Nueva España; entre ellos se hallaban varios miembros del Colegio de Abogados. Ese mismo día el rector José Antonio Torres Torija dio cuenta, ante una nutrida concurrencia, del oficio del virrey Venegas

en que previene se exhorte a los individuos de este ilustre cuerpo a que escriban acerca de los bienes que produce la unión y males de la división a fin de fundar la opinión pública y desterrar las preocupaciones que han dado pábulo a la presente insurrección suscitada por el cura Hidalgo y sus secuaces.

En esa misma sesión se decidió que a más del documento suscrito por el colegio, los miembros podían escribir por separado. ${ }^{47}$ Este acto muestra claramente la reacción de la corporación hacia los insurgentes. No están entre los asistentes a la junta ni López Matoso, ni Domínguez Manzo, ni Peimbert, pero sí asistieron los Guerra, García, Mariano Castañeda y Sotero Castañeda.

La insurrección no llegó a conseguir el apoyo de los cuerpos académicos o profesionales de Nueva España. Al ser equiparada por las autoridades a la revolución francesa, insistiendo en que acabaría como ésta, enderezándose contra la religión católica, ${ }^{48}$ las di-

47 Archivo del Colegio de Abogados, Juntas, de la fecha.

48 Basta ver la literatura de la época para constatar que ésta fue la posición de las autoridades, véase Garritz, Imipresos, 1990-1991. versas corporaciones acabaron condenando la insurgencia en términos semejantes a los que expuso el Claustro de la Universidad, para cuyos integrantes: "sin sacudir el yugo del Evangelio, no podemos sacudir el de la potestad soberana que nos rige". 49 No era fácil pasar por alto la reiterada condena de las autoridades civiles y eclesiásticas. Pero no sólo eso, sino que también debieron ver en la insurrección una amenaza contra sus privilegios, su posición, su estatus.

Es, pues, comprensible la reacción del Colegio de Abogados, en cuyo seno en la reunión que había convocado el rector se produjo una alocución publicada el propio año de 1810 en la que se rechaza la propuesta hecha por los insurgentes de hallarse los americanos en situación desigual frente a los españoles; se argumenta en favor de la gran obra de los reyes en la edificación de iglesias; se celebran las bondades de la legislación, ya que la Recopilación de Indias era el escudo de la religión y que las leyes dictadas por los reyes habían favore. cido la industria, las letras y las ciencias; se insiste en la unión entre las Indias y la corona de Castilla, con la cual formaban un sólo cuerpo, y en las ventajas de la unión entre españoles y americanos; se afirma que ya hay igualdad entre españoles y americanos e incluso diputados de éstos a las Cortes, y se conmina a los ciucladanos a seguir luchando por el rey Fernando VII. Firman Torres Torija, Torres Cataño, Primo de Rivera, López

49 Hernández y Dávalos, Historia, 1985, vol. 1, p. 147; "Manifiesto de 5 de octubre de 1810 contra la rebelión", las cursivas son mías. 
Matoso y García y García, entre muchos otros. ${ }^{50}$ Según lo convenido, algunos abogados escribieron por separado contra la insurrección y sus banderas. Antonio López Matoso y Juan Wenceslao Sánchez de la Barquera, miembros ambos del Colegio y Guadalupes o simpatizantes de ellos, ${ }^{51}$ defendieron la unión y rechazaron los vocablos de criollo y gachupín, utilizados para fomentar la división entre españoles y americanos. El primero señala que la extravagancia de distinguir a unos de otros "turba el orden social", "destruye la paz pública" y "es contraria, con una oposición inconciliable, al derecho natural, a los consejos del evangelio a la justicia, y al honor y a las máximas de gratitud".52 Uno y otro convocan a luchar en favor de Fernando VII.

A finales del año de 1814, en el mes de diciembre, con diferencia de unos cuantos días se produjeron dos convocatorias, el día 4 la de la regencia dirigida a los españoles de las Indias exhortándolos a mantenerse unidos, ya que la nación española de uno y otro hemisferio era una sola; ${ }^{53}$ y el día 15 la del Manifiesto de Morelos al pueblo, convocándolo a un Congreso alterno a las Cortes de Cádiz. ${ }^{54}$

En el año 1811 se aprobaron las constituciones de la Academia Pública de Jurisprudencia Teórico Práctica y

so Alocución, [1810]. La reunión se celebró el 29 de octubre de 1810.

51 A. L. M. [Antonio López Matoso], Exhortación, 1810; J. W. B. UJuan Wenceslao Sánchez de la Barquera], Refutación, 1810.

52 López Matoso, Exbortación, 1810, p. 8.

53 Hernández y Dávalos, Historia, 1985, vol. II, pp. 252-255.

St Ibid., vol. n, p. 303.
Derecho Real Pragmático, el 11 de enero, con lo cual el colegio asumía el control sobre la formación teórico práctica de todos los abogados en potencia. Por otra parte, ese mismo año por decreto de las Cortes de Cádiz de 22 de abril del mismo año de 1811, se abría la entrada al colegio a cuantos abogados lo solicitaran dando fin a la política de restringir su número.

Así pues, mientras el colegio, como cuerpo, cosechaba las mieses del trabajo realizado y de su lealtad a las instituciones, muchos de sus miembros se sumaron, individualmente, a la insurrección y las diversas conspiraciones de la época. Tal puede concluirse del hecho de que en las dos que se realizaron en contra del virrey Venegas a lo largo de 1811 se halla. ban involucrados miembros del Colegio de Abogados: Jacobo de Villaurrutia, Antonio López Matos, José An. tonio Flores Alatorre, Flores Cataño, Peimbert y Castillejos, entre otros, en la de abril, y José Ferrer en la de agosto, ${ }^{55}$ y quizá algunos otros por lo que luego se verá. Asimismo, en las elecciones de 1811, muchos de los conjurados del partido criollo eran del Colegio de Abogados. ${ }^{56} \mathrm{La}$ participación de los colegiales en luchas y conspiraciones llevó a la reducción obligada del número de abogados que compartían la vida institucional, que se reducía, cada vez más, a las sesiones de la Academia de Jurisprudencia Tébrico Práctica y a la asistencia a sus estudios.

55 Anna, Catda, 1981, pp. 96-99; De la Torre Villar, "Guadalupes", 1966, p. 74.

56 Guedea, "Busca", 1990. 


\section{La lucha dentro del orden constitucional}

En enero de 1812, el Colegio de Abogados solicitó la modificación del artículo $7^{\circ}$ del quinto de sus estatutos para que las juntas que se celebraban con 50 individuos, conforme a dicho texto, pudieran ser válidas con tan sólo 30.57 Es ésta una prueba clara de la reducción de la concurrencia a las sesiones del colegio, el cual, frente a los acontecimientos, optó por hacer la crítica del régimen imperante, estrictamente discursiva, arropada con un fino lenguaje teórico.

En marzo de 1812 se promulgó la ansiada Constitución, pero su jura en el virreinato demoró varios meses, por el estado de permanente conflicto causado por la insurrección. El virrey Venegas creía -y con razón- que con su juramento se avivaría el fuego autonomista. Tras mucho darle vueltas, el 30 de septiembre Venegas, la Audiencia, el Ayuntamiento y las demás autoridades juraron la Constitución Pólítica de la Monarquía Española.

$\mathrm{Al}$ arreciar la carga de los insurrectos y de sus seguidores contra las autoridades, Venegas, por acuerdo de la Audiencia, suspendió la libertad de imprenta el 5 de diciembre del primer año de vigencia de la Constitución.

El 26 de marzo de 1813 asumió el gobierno Félix María Calleja, y en la proclama que dirigió a los habitantes advirtió con claridad que castigaría "irremisiblemente a los obstinados y malévolos" que siguieran empeñados en la destrucción del vi-

57 AGN, Escribanos, vol. 23, exp. 20, f. 217. rreinato y atentaran contra la seguridad del Estado. ${ }^{58}$ Sobre advertencia no hay engaño, habrán pensado los abogados que prepararon -sin libertad de imprenta- pero con la Constitución vigente una solemne acción de gracias, dedicada a Calleja, en honor de las Cortes generales y extraordinarias que habían dictado la Constitución Política de la Monarquía Española. ${ }^{59}$

La sesión se caracterizó por el vigor de la argumentación de los abo. gados en beneficio de las tesis que preconizaban que la soberanía residía en la nación y en el señalamiento teórico de algunas de las más importantes contradicciones del texto constitucional de Cádiz. Todo ello fue po. sible porque de acuerdo con los estatutos, el orador expondría las virtudes de la Constitución y los replicantes harían la crítica. El tema elegido fue el artículo $3^{\circ}$, esto es, el que se refiere a la soberanía. La crítica se mantuvo dentro de posiciones "nacionalistas", ya no autonomistas, porque la unidad de la monarquía era una realidad consagrada en el propio texto constitucional. Para los abogados, criollos en buen número, congregados en la solemne sesión, la soberanía residía, siguiendo el texto gaditano, en la nación. En tanto que los abogados que seguían a Morclos -también criollos muchos de ellos-se disponían a elaborar un texto constitucional sobre el modelo rousseauniano de soberanía, esto es la que reside en el pueblo.

58 De la Torre Villar, "Guadalupes", 1966, p. 12.

${ }^{59}$ Solemne, 1814. 
Consecuentes con el texto cuya promulgación celebraban, los abogados se adherian, al menos formalmente, a la propuesta de la monarquía constitucional con Fernando VII a la cabeza. Los participantes en el acto fueron Benito José Guerra, Juan Francisco de Azcárate y Juan Gómez de Navarrete; orador el primero y replicantes los otros dos.

El comentario de Azcárate señala cuestiones de gran importancia sobre el tema, ya que dice que la Constitución haría la felicidad de todos, menos la del rey, a quien se despojaba del ejercicio del poder absoluto bajo el cual asumió y juró el cargo. ${ }^{60}$ Gómez de Navarrete, por su parte, advirtió a la concurrencia que al regreso de Fernando VII a su trono la Constitución sería semillero de discordias y germen de disturbios y partidos, lo que precipitaría a la nación a la guerra civil. ${ }^{61}$

En sus críticas coincidían estos abo. gados con el virrey Calleja que, desde otra perspectiva, en el informe enviado al Ministerio de Gracia y Justicia sobre la situación que privaba en Nueva España en 1813, externó que los naturales sólo recibían la Constitución "como un medio que puede proporcionarles llevar a cabo sus intenciones con inmensos obstáculos y dificultades", obstinados -como estaban- "en su mal propósito de independencia y segregación de la península". Para justificar la proscripción de la libertad de imprenta ${ }^{62}$ adujo que los escritores rebeldes habían desatado

60 Ibid., pp. 28-40.

61 lbid., pp. 49-60; cita en p. 54.

62 La cual ya no se restableció. "una guerra incontrastable" aprovechándose de las luces y de los principios liberales del Congreso. ${ }^{63}$

A finales del año 1813, el 6 de noviembre, Morelos expidió el Acta Solemne de la Declaración de Independencia de la América Septentrional, firmada -entre otros- por Carlos María de Bustamente, miembro que habia sido del Colegio de Abogados y el 22 del mismo mes la Academia todavía se dio tiempo para celebrar un Ejercicio Literario en honor del obispo Bergosa y Jordán. Se fijó como tema el artículo 12 de la Constitución de Cádiz, esto es el que consagraba el principio de que la religión de la monarquía sería per. petuamente la católica. En esta sesión participó Manuel de la Peña y Peña, como orador, y realizaron las réplicas Agustín Pérez de Lebrija y Mariano Miranda. ${ }^{64}$ Como el tema era la religión católica y todos eran fidelísimos a ella, la tónica del ejercicio fue de aducir, con poca pasión, las críticas comunes que se le hacían, entre otras, que disminuía la población por el gran número de habitantes que no contraían matrimonio.

Para la fecha de la sesión citada, mucho habían cambiado las cosas de Nueva España. Calleja consolidaba su triunfo contra los insurgentes. De los abogados que se habían unido a éstos, algunos se hallaban muertos, otros, los 29-31.

${ }^{63}$ De la Torre Villar, "Guadalupes", 1966, pp.

64 Hay también una preterición de Agustín Pomposo Fernández de Sansalvador; un epigrama y un soneto de José María Larrañaga y una especie de corolario de Mariano Primo de Rivera, véase Hemández y Dávalos, Historia, 1985, vol. v, pp. 218-238. 


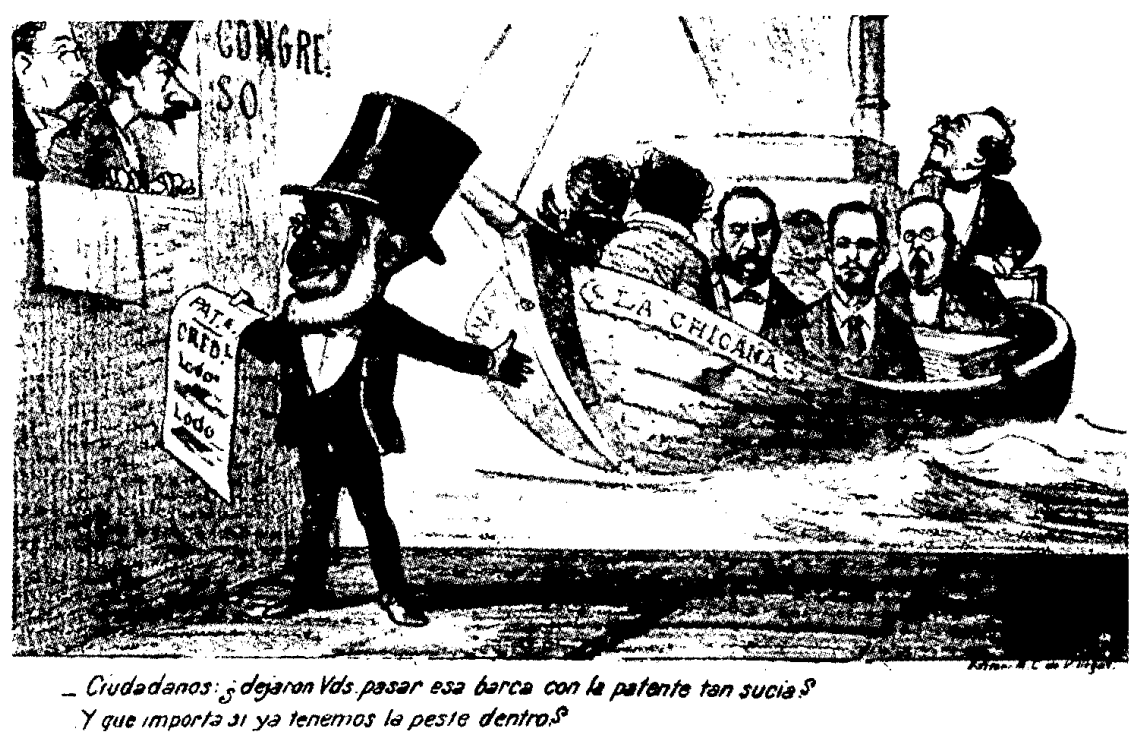

que sólo habian simpatizado con la insurrección, habían sido desterrados o suspendidos en sus empleos, aunque esta suspensión en muchos casos fue más formal que real, por la amplitud que había alcanzado la conspiración autonomista.

De cualquier manera, las medidas adoptadas por los virreyes, especialmente por Calleja, convencieron a los abogados que permanecieron en el colegio de la conveniencia de ejercer la crítica de las instituciones sólo en los casos señalados en el Estatuto.

\section{La institucionalidad dentro del absolutismo}

En enero de 1814 las Cortes abrieron sesiones y se prepararon para recibir al monarca, quien habría de jurar -se pensaba- la Constitución de Cádiz. En febrero entró Fernando VII en España. Pronto comenzaron los embates contra la Constitución, encabezados por el grupo de diputados conservadores llamados "persas". En mayo, el monarca español disolvió las Cortes y anuló la Constitución, los diputados liberales fueron detenidos al tiempo que entraba en Madrid Fernando VII. En junio se informó en Nueva España del regreso del monarca a su trono y el virrey Calleja dispuso que el hecho se festejara durante tres días; la noticia de haber sido abolida la Constitución se dio a conocer por bando del virrey de 10 de agosto.

El 16 de octubre se realizó una Jun- 


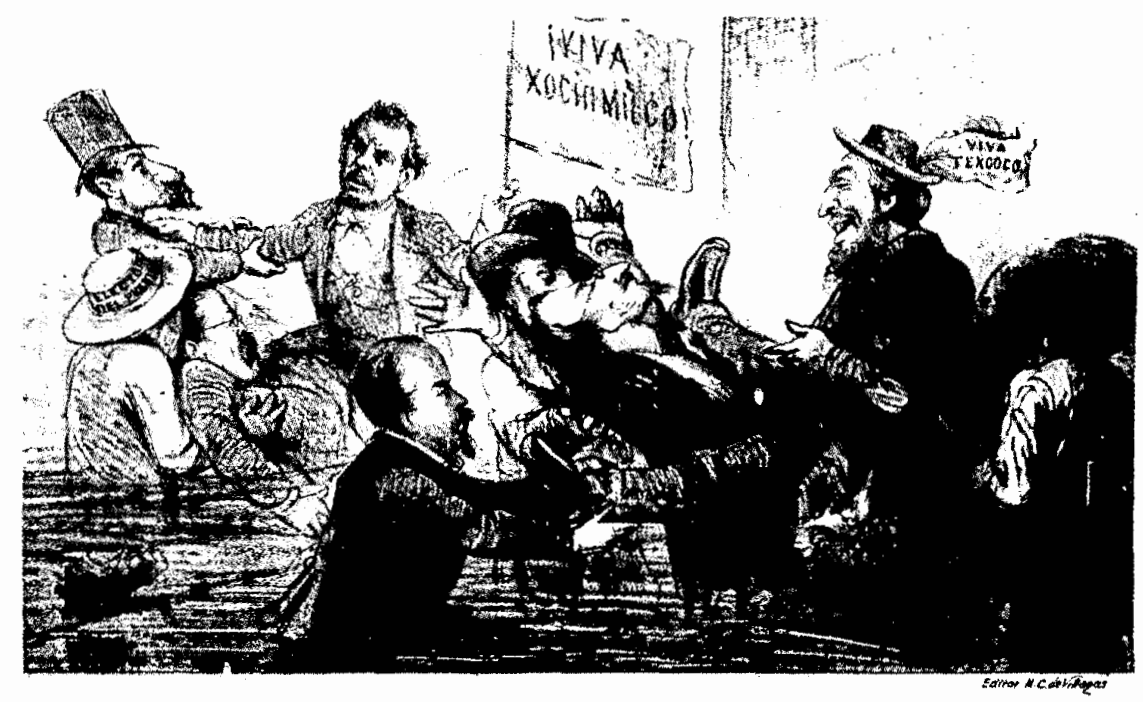

Lucha electoral del Pueblo.

ta General en el seno del Colegio de Abogados para atender la propuesta del virrey de solemnizar en forma adecuada "el feliz suceso de la restitución cle nuestro amado y deseado monarca el señor don Fernando VII". La concurrencia y el tono de reunión contrastan con el de las anteriores, aunque el virrey haya hecho un "enérgico discurso" exhortando a todos a mos. trar su "regocijo y alegría" por el acontecimiento. ${ }^{65}$

No se puede saber, porque no lo dijeron, qué pensaban de la abrogación del texto constitucional al que tantas loas habían dedicado poco tiempo an-

65 Archivo del Colegio de Abogados, Juntas, de la fecha. La concurrencia fue poco nutrida, contrastada con la del año 1810 , por ejemplo. tes. Pero en la junta se percibe su estado de ánimo ya que, cuando se hicieron propuestas para la realización de los festejos, se decidió solamente hacer una misa de acción de gracias, concluida la cual se cantaría un $T e$ Deum. Para la celebración del evento se pidió a los abogados que iluminaran y adornaran sus balcones, "por ser la única demostración que puede ejecutar el colegio en las circunstancias de la grande escasez en que se hallan todos". Se justificó la pobreza del festejo aludiendo al decaimiento económico del reino, la miseria y la depresión que habían sufrido los estu. dios de los abogados. Sobra decir que en la sesión ya no estaba ni Lópcz Ma. toso, ni Domínguez Manzo, ni Sotero Castañeda, ni Guerra. Curiosamente 
sí se hallaban presentes Peimbert y Navarrete, $y$ no Peña y Peña. El rector era Mariano Primo de Rivera. ${ }^{66}$

Los acontecimientos que siguen muestran el fin de la opción de lucha dentro de las instituciones por conseguir la autonomía. Por un lado, el 22 de octubre se promulgó en Apatzingán el Decreto Constitucional para la libertad de la América Mexicana, y por el otro, triunfante, Calleja publicó un bando el 15 de diciembre sobre la abolición de la Constitución y para disolver el Ayuntamiento constitucional de la ciudad de México, ${ }^{67}$ retornando todo al estado que guardaba el 1 de mayo de 1808 . El ciclo se había ce. rrado y los sueños autonomistas de los abogados no pudieron hacerse realidad.

De lo que se lleva dicho se puede ver que la lucha de los miembros del Colegio de Abogados fue, salvo excepciones, dentro del marco de las instituciones. El carácter político de la corporación no puede ser negado, sólo hay que insistir en las peculiaridades del modo de ejercer su influencia como cuerpo. Este modo no podía ser otro que el que aprendían en los largos años de su formación: el que señalaban la doctrina jurídica y las leyes. Así, de un lado, en ocasiones parecen mostrar una conducta autónoma pero, al topar con la respuesta del régimen establecido, acaban adhiriéndose al marco institucional, del que formaban parte y dentro del cual tenían privilegios. Del otro, y con ello trato de marcar el contrapunto, está la acción

${ }^{66}{ }_{A G N}$, Escribanos, vol. 29, exp. 7, ff. 94-99.

67 Guedea, "Elecciones", 1991, pp. 1-28. de los que abrazaron la insurgencia. El camino era el mismo aunque éstos tuvieran en mente otra forma de Estado, ya que también buscaban establecerlo de acuerdo con lo que marcaran una Constitución y unas leyes sustentadas en el bagaje jurídico romano-canónico enriquecido con las ideas del racionalismo iluminista y con las tesis del liberalismo, enriquecidas a su vez con las leyes y doctrinas angloamericanas.

\section{Bibliografía}

Alocución del Real e Ilustre Colegio de Abogados de México, [México, 1810].

-Anna, Timothy, La caida del gobierno español en la ciudad de México, Fondo de Cultura Económica, México, 1981.

-Arenal Fenochio, Jaime del, "Los abogados en México y una polémica centenaria (1784-1847)", Revista de Investtgaciones Juridicas, núm. 4, 1980, pp. 544-549.

-Bermúdez Aznar, Agustín, Contribución al estudio del corporativismo curial, El Colegio de Abogados de Murcia, Sucesores de Nogués, Murcia, España, 1969.

-Berruezo, María Teresa, La participa. ción americana en las Cortes de Cádiz, 1810-1814, prólogo de José Luis Abellán, Centro de Estudios Constitucionales, Madrid, 1986.

-Burkholder, Mark A., y D.S. Chandler, De la impotencia a la autoridad. La corona española y las audienclas en Amérfca, 1687.1808, Fondo de Cultura Ecónomica, México, 1984.

-Estatutos del Ilustre y Real Colegio de Abogados nuevamente reformados $y$ añadidos con aprobación superior; conforme a la real cédula de su evección, Imprenta en la Oficina de Arizpe, México, 1808.

-Estatutos del Nacional Colegio de Abogados de Méxtco. Reformados el año 
de 1828, octavo de la independencia, séptimo de la libertad y quinto de la República, Imprenta del Âguila, dirigida por José Ximeno, México, 1830.

-García, Genaro, Documentos Históricos Mexicanos, Consejo Nacional de Fomento Educativo, México, 1985, edición facsimilar de la que se publicara en México, Museo Nacional de Arqueología, Historia y Etnología, 1910.

-Garritz, Amaya, Impresos novobispanos, 1808-1821, 2 vols., Universidad $\mathrm{Na}$ cional Autónoma de México-Instituto de Investigaciones Históricas, México, 19901991.

González, María del Refugio, "La Academia de Jurisprudencia Teórico-Práctica de México. Notas para el estudio de su labor docente (1811-1835)", Revista de Investigaciones Juridicas, año VI, núm. 6, México, 1982.

, "La práctica forense y la Academia de Jurisprudencia Teórico-Práctica de México (1834-1876)", en Memoria del III Congreso de Historia del Derecho Mextcano, Universidad Nacional Autónoma de México-Institu to de Investigaciones Jurídicas, México, 1984.

, "La enseñanza y la investigación del derecho", Pensamiento Universilario, nueva época, núm. 70, Universidad Nacional Autónoma de México-Centro de Estudios sobre la Universidad, México, 1987.

-González del Campillo, Manuel Ignacio, Pastoral que el Ilustrisimo señor doc. tor $D$. .... dignisismo obispo de Puebla de los Angeles dirige a sus diocesanos, [Puebla], [s.p.i.], 1810.

-Guedea, Virginia, "Las primeras elecciones populares en la ciudad de México. 1812-1813", Mexican Studies/Estudios Mexicanos, vol. 7, núm. 1, invierno de 1991, pp. 1-28.

, "En busca de un gobierno alterno. Los Guadalupes de México", tesis de doctorado, Facultad de Filosofia y Letras, México, 1990.

-Hernández y Dávalos, Historia de la Guerra de Independencia de México, Instituto Nacional de Estudios Históricos de la Revolución Mexicana, México, 1985 (edición facsimilar).

-[López Matoso, Antonio], Exbortación que a los babitantes de México bace un individuo del Ilustre Colegio de Abogados, relator de esta Audiencia, Casa de Arizpe, México, 1810.

-Maravall, José Antonio, "La formación de la conciencia estamental de los letrados", Revista de Estudios Políticos, Madrid, núm. 70, julio-agosto, 1953.

-Mariluz Urquijo, José M., "El Teatro de La Legislación de España e Indias y otras recopilaciones indianas de carácter privado", Revista de Historia del Derecbo, s.a.

-Pérez de Villamil, Juan, Diserración sobre la libre multitud de abogados, Madrid, s.a.

-Plaza y Jaén, Cristóbal Bernardo de la, Crónica de la Real y Pontificia Universi. dad de México, versión paleográfica, proemio, notas y apéndices de Nicolás Ranget, Universidad Nacional Autónoma de México, 1931, vol. I.

-[Sánchez de la Barquera, Juan Wenceslao], Refutación de un español a los principales artículos de las proclamas de José Bonaparte. Que de orden del superior gobierno se ban quemado públicamente por mano de verdugo en esta capital, Mariano Zúñiga y Ontiveros, México 1810.

-Schulz, Fritz, History of roman legal science, Oxford University Press, Oxford, 1967.

Solemne acción de gracias que la Academia de Derecbo Español, Público y Privado de la capital de México da al Supremo Congreso de las Cortes Generales y Extraordinarias por baber dictado la Constitución Política de la Monarquia 
Española, celebrada el día 15 de marzo de 1813. En el Aula Mayor del Colegio más antiguo de San Pedro, San Pablo y San Ildelfonso, con superior permiso, Imprenta de doña María Fernández de Jáuregui, México, 1814.

-Tena Ramírez, Felipe, Leyes fundamentales de México, 1808-1976, Editorial Porrúa, México, 1976.
-Tocqueville, Alexis de, La democracta en América, traducción de Luis R. Cuéllar, prefacio, notas y bibliografia de J. P. Mayer, Fondo de Cultura Económica, México, 1987.

-Torre Villar, Ernesto de la, Los "Guadalupes" y la independencia, con una selecctón de documentos inéditos, Editorial Jus, México, 1966. 